\title{
Laser spectroscopic real time measurements of methanogenic activity under simulated Martian subsurface analog conditions
}

\author{
Janosch Schirmack $^{\mathrm{a}, *}$, Michael Böhm ${ }^{\mathrm{b}}$, Chris Brauer ${ }^{\mathrm{b}}$, Hans-Gerd Löhmannsröben ${ }^{\mathrm{b}}$, \\ Jean-Pierre de Vera ${ }^{c}$, Diedrich Möhlmann ${ }^{\mathrm{c}}$, Dirk Wagner ${ }^{\mathrm{d}, *}$ \\ a Alfred Wegener Institute for Polar and Marine Research, Research Unit Potsdam, Telegrafenberg A45, 14473 Potsdam, Germany \\ ${ }^{\mathrm{b}}$ University of Potsdam, Department of Chemistry, Physical Chemistry, innoFSPEC Potsdam, Karl-Liebknecht-Str. 24-25, 14476 Potsdam, Golm, Germany \\ ${ }^{\text {c } G e r m a n ~ A e r o s p a c e ~ C e n t e r ~(D L R), ~ R u t h e r f o r d s t r a ß e ~ 2, ~} 12489$ Berlin, Germany \\ ${ }^{\mathrm{d}}$ Helmholtz Centre Potsdam, German Centre for Geosciences (GFZ), Section 4.5 Geomicrobiology, Telegrafenberg, 14473 Potsdam, Germany
}

\section{A R T I C L E I N F O}

\section{Article history:}

Received 19 December 2012

Received in revised form

9 August 2013

Accepted 23 August 2013

Available online 31 August 2013

\section{Keywords:}

Mars

Methanogens

Methane

Sub-zero temperature (Celsius)

Wavelength modulation spectroscopy (laser spectroscopy)

\begin{abstract}
A B S T R A C T
On Earth, chemolithoautothrophic and anaerobic microorganisms such as methanogenic archaea are regarded as model organisms for possible subsurface life on Mars. For this reason, the methanogenic strain Methanosarcina soligelidi (formerly called Methanosarcina spec. SMA-21), isolated from permafrostaffected soil in northeast Siberia, has been tested under Martian thermo-physical conditions. In previous studies under simulated Martian conditions, high survival rates of these microorganisms were observed. In our study we present a method to measure methane production as a first attempt to study metabolic activity of methanogenic archaea during simulated conditions approaching conditions of Mars-like environments. To determine methanogenic activity, a measurement technique which is capable to measure the produced methane concentration with high precision and with high temporal resolution is needed. Although there are several methods to detect methane, only a few fulfill all the needed requirements to work within simulated extraterrestrial environments. We have chosen laser spectroscopy, which is a non-destructive technique that measures the methane concentration without sample taking and also can be run continuously. In our simulation, we detected methane production at temperatures down to $-5^{\circ} \mathrm{C}$, which would be found on Mars either temporarily in the shallow subsurface or continually in the deep subsurface. The pressure of $50 \mathrm{kPa}$ which we used in our experiments, corresponds to the expected pressure in the Martian near subsurface. Our new device proved to be fully functional and the results indicate that the possible existence of methanogenic archaea in Martian subsurface habitats cannot be ruled out.
\end{abstract}

(c) 2013 Published by Elsevier Ltd.

\section{Introduction}

Although Mars is considered to be the most Earth-like planet of our solar system, its present conditions are characterized as extreme cold and dry. However, there is evidence that $3.8 \mathrm{Ga}$ ago the environmental conditions of early Mars and early Earth have been very similar (Carr, 1989, 1996; Durham et al., 1989; McKay and Davis, 1991; McKay et al., 1992). Considering this, there is the given possibility of life emerging on Mars during the same time as life first appeared on Earth. After its hypothetical initial evolution, life on Mars either might have become extinct resulting in only fossil records being found today, or it might have adapted to the

\footnotetext{
* Corresponding author. Tel.: +49 331288 2142; fax: +49 33128828802.

* Corresponding author. Tel.: +49331288 28800; fax: +49331 28828802.

E-mail addresses: Janosch.Schirmack@awi.de (J. Schirmack),

Dirk.Wagner@gfz-potsdam.de (D. Wagner).
}

drastically changing conditions and still may be present in some ecological niches.

Spectroscopic observations from the ESA Mars Express spacecraft (Formisano et al., 2004; Geminale et al., 2011) and ground based spectra analysis from Earth (Krasnopolsky et al., 2004; Mumma et al., 2009) have detected trace amounts of methane in the Martian atmosphere. Direct photolysis by solar UV radiation and homogenous oxidation by $\mathrm{OH}$ and $\mathrm{O}\left({ }^{1} \mathrm{D}\right)$ are believed to cause a relatively short lifetime of methane on Mars of approximately 340 years (Gough et al., 2010; Krasnopolsky et al., 2004). This leads to the assumption, that the observed methane must have a recent origin on the planet. At the time of writing latest measurements performed with the Tunable Laser Spectrometer on board of the Curiosity Rover indicated no definitive detection of methane on Mars, with a measured value of only $0.55 \pm 1.46 \mathrm{ppbv}$, at least for Gale Crater region (Webster et al., 2013). This stands in contrast to the predicted global average value of about $10-15$ ppbv methane (Formisano et al., 2004; Geminale et al., 2011). Nevertheless 
sources of methane on Mars could be abiotic either via active volcanism, which has not yet been observed on Mars (Krasnopolsky, 2006), or formation via Fischer-Tropsch reactions associated with serpentinization (Michalski et al., 2013; Oze and Sharma, 2005; Vance et al., 2007). Another possible source for methane would be biogenic production. Although the spectroscopic detection of methane on Mars has been discussed critically (Zahnle et al., 2011), the observed spatial and temporal variation of methane in the Martian atmosphere (Formisano et al., 2004; Geminale et al., 2008, 2011) and its correlation with the presence of water vapor are supporting the biogenic production theory. On earth aerobic methane production by plants is also known (Bruhn et al., 2012), but the main biological source of terrestrial methane is anaerobic methanogenesis (methane production by methanogenic archaea e.g. Barbier et al., 2012; Bischoff et al., 2012). For this reason several scientific publications have previously dealt with methanogenic archaea as model organisms for possible life on Mars (Boston et al., 1992, Jakosky et al., 2003, Kral et al., 2004, 2011; Krasnopolsky et al., 2004; Morozova et al., 2007; Morozova and Wagner 2007; Ulrich et al., 2012; Weiss et al., 2000).

Methanogenic archaea from Siberian permafrost environments have shown extraordinary tolerance against different environmental stresses. However, previous tests were not able to reveal if the microorganisms could be metabolically active in a Mars-like environment or merely were able to survive by entering a dormant state. The methanogenic strain we are using in our recent experiments is Methanosarcina soligelidi (formerly called Methanosarcina spec. SMA-21), which has been isolated from the active layer of a permafrost-affected soil in northeast Siberia (Wagner et al., 2013). In direct comparison to reference strains from non-permafrost environments $M$. soligelidi has shown high resistances against long term freezing for up to two years at $-20^{\circ} \mathrm{C}$, high salt concentrations up to $6 \mathrm{M} \mathrm{NaCl}$ and starvation (Morozova and Wagner, 2007), as well as high doses of UV and ionizing radiation (Wagner, D., unpublished data). Along with two methanogenic strains isolated from the Lena Delta, $M$. soligelidi survived three weeks of simulated Martian thermo-physical conditions (Morozova et al., 2007). This was done with a diurnal profile in a Mars-like atmosphere $\left(95.3 \% \mathrm{CO}_{2}, 0.6 \mathrm{kPa}\right)$ with temperature fluctuations from +20 to $-75^{\circ} \mathrm{C}$ and varying humidity with $a_{\mathrm{w}}$-values between 0.1 and 0.9 corresponding to the Mars average equivalent water vapor pressure of $0.1 \mathrm{~Pa}$. Three in parallel tested reference strains from non-permafrost environments did not show any activity after the simulation period, whereas $M$. soligelidi had almost the same activity than before.

The aim of this study is to present a method to measure the methane production of methanogenic archaea under defined thermo-physical conditions in real time without affecting the simulation conditions through removal of gas samples as it would be necessary for gas chromatography. We developed a system in which we combine laser spectroscopic methane detection with a simulation chamber. In this first study we are focusing on simulated Mars analog subsurface conditions regarding temperature and pressure like would be found in a potential deep biosphere.

\section{Methods}

\subsection{Wavelength modulation spectroscopy}

With laser spectroscopy one can very specifically measure the absorption of methane in the gas phase. With careful selection of the absorption line, cross sensitivities to other gases can be ruled out. Here, we choose the strong absorption line at $1653.45 \mathrm{~nm}$ $\left(6047.95 \mathrm{~cm}^{-1}\right)$, to avoid cross sensitivity to water or carbon

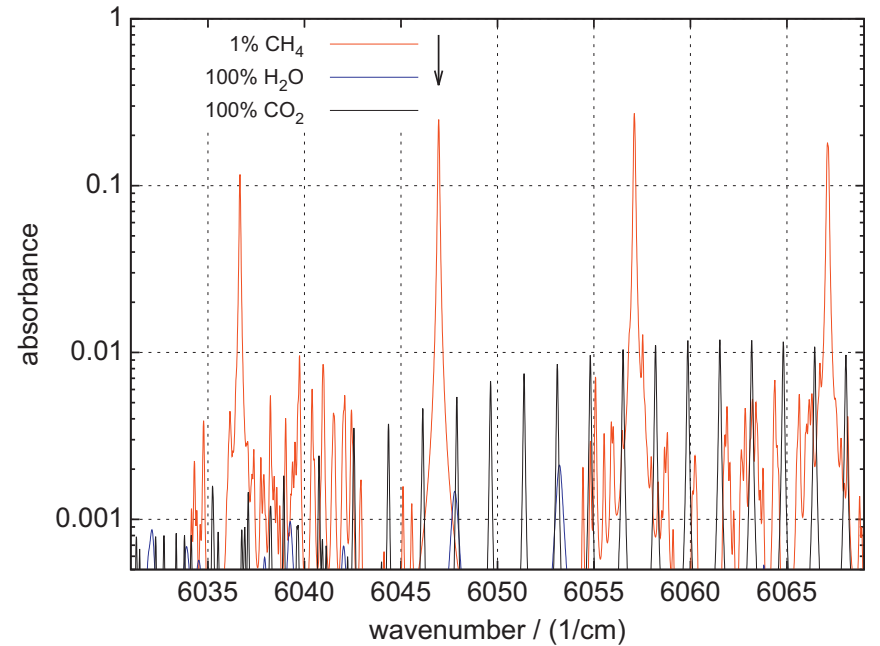

Fig. 1. Comparison of the absorption of $1 \% \mathrm{CH}_{4}$ (red curve), $100 \% \mathrm{CO}_{2}$ (black curve) and $100 \% \mathrm{H}_{2} \mathrm{O}$ (blue curve) for $1 \mathrm{~m}$ optical path at $50 \mathrm{kPa}$ and $296 \mathrm{~K}$ according to the Hitran database. The marked line was chosen to detect methane, because it is strong and avoids cross sensitivites. (For interpretation of the references to color in this figure legend, the reader is referred to the web version of this article.)

dioxide (HITRAN database: Rothman et al., 2009), as shown in Fig. 1. Although there are stronger absorption lines in the mid infrared, the near infrared spectral region is better addressable because of readily available laser-based telecommunication equipment. For instance, the distributed feedback laser, which was used in this work, is from the telecom provider Anritsu (GB6B5004BDP; Japan). This fiber coupled laser emits $\mathrm{cw}$-light with several $\mathrm{mW}$ of optical power, which is tunable across the entire methane line. A highly sensitive InGaAs-photodiode is used (Thorlabs PDA10CSEC; Newton, New Jersey, USA) to detect the light. Such a near infrared system is less expensive than mid infrared ones, which use e.g. quantum cascade lasers. A near infrared system, like the one presented here, is also better when building up several such devices in parallel. Such a parallel detection scheme seems to be necessary for a systematic analysis of methane production under various conditions.

Due to laser power fluctuations, simple absorption spectroscopy is not sensitive enough and thus a more sophisticated method is needed. Here we use wavelength modulation spectroscopy (Demtröder, 2007). The current of the laser diode is controlled to vary the wavelength of the emitted light (Thorlabs ITC 502; Newton, New Jersey, USA). With lock-in detection technique (lock-in amplifier from Stanford Research System SR830 DSP; Sunnyvale, California, USA), strong rejection of laser fluctuations, background light and noise is achieved.

The experimental setup is shown schematically in Fig. 2. For a given center wavelength, the laser output wavelength is varied sinusoidal. This modulated light passes the measuring chamber and is analyzed by the lock-in amplifier after detection. The lock-in signal is measured as a function of center wavelength. The received data were recorded every $6 \mathrm{~min}$, and the concentration was determined by fitting to the data, as described in more detail below (see Section 2.2).

The production of methane takes place in the liquid phase, but the detection is performed in the gas phase. Therefore, the methane must out-gas from the water, which is a slow process. To increase the out-gassing rate, our growth chamber has a high surface to volume ratio (see Section 2.3). For an effective measurement a large optical path length is needed. The presented device has an optical path length of $1.7 \mathrm{~m}$ with a gas volume of $590 \mathrm{ml}$ and is shown in Fig. 3a. A better method for increasing the beam path length to gas volume ratio would be given by an approach 
presented by Cubillas et al. (2009) for measuring methane. However, due to the complexity of this approach it was not investigated here.

\subsection{Calibration}

Although there are methods for quantitative calibration-free and reference-free wavelength modulation spectroscopy (Zakrevskyy et al., 2012), we calibrated the whole setup using a reference gas $\left(10,000 \mathrm{ppm}\right.$ methane in $\left.\mathrm{N}_{2}\right)$. Calibration was performed for different pressures and different dilutions, which is shown in Fig. 4. The received data were fitted assuming a Gaussian shaped spectral line. As a measure for the concentration the area retrieved from the fit is used. Since this kind of fitting is prone to systematic errors, we used 210 calibration points with known concentration, pressure and temperature of the gas resulting in a nonlinear calibration curve (Fig. 4). For each concentration and pressure three measurements were performed to check reproducibility. A fit to the calibrated data is used to derive a conversion function for the measured data with unknown concentration. Additionally, before and after a measured simulation sequence, we cross checked the validity of the calibration with a single point measurement using the reference gas. This procedure ensures,

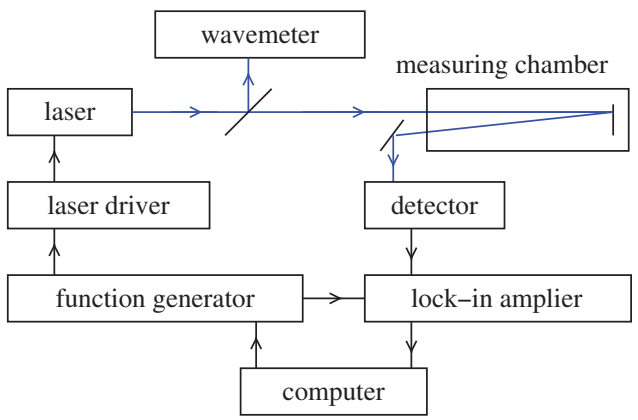

Fig. 2. Schematic diagram of the used wavelength modulation spectroscopic technique: a function generator is used to modulate the laser wavelength via a laser driver, while the actual wavelength is monitored with a wavemeter. The light is, after passing through the measuring chamber, detected with an InGaAsphotodiode. The signal from the detector is then analyzed with lock-in technique. The lock-in signal is finally recorded as a function of the optical center wavelength. that even in the case of a residual systematic error in the absolute calibration an increase of the methane concentration is not observed due to a wrong calibration.

To calibrate the wavelength, a wavelength meter WA1100 (Burleigh; Victor, New York, USA) was used achieving a resolution in the order of several pm.

\subsection{Two chamber simulation system}

Since the methane production should be investigated for different temperatures and pressures, a growing chamber (made of glass), which is surrounded by a controllable temperature flow of oil (Lauda Pro Line RP845; Lauda-Königshofen, Germany) was used, as shown in Fig. 3b. The pressure was set and recorded with a pressure sensor (Vacuubrand DVR5; Wertheim, Germany). The growing chamber was in gas flow contact with the measuring chamber (Fig. 3a). The measuring chamber was thermally isolated from the lab conditions and was kept at a constant temperature of $22{ }^{\circ} \mathrm{C}$ (Lauda Ecoline RE 306; Lauda-Königshofen, Germany) for easy spectroscopic calibration of the methane concentration. The scheme of the two chamber setup is shown in Fig. 5.

\subsection{Organism and growth media}

The strain Methanosarcina soligelidi was isolated from the active layer of permafrost-affected soil on Samoylov Island in the delta of the river Lena in northeast Siberia $\left(72^{\circ} 22^{\prime} \mathrm{N}, 126^{\circ} 28^{\prime} \mathrm{E}\right.$; Wagner et al., 2013). The cells of $M$. soligelidi were incubated under strict anaerobic conditions in $125 \mathrm{ml}$ serum bottles sealed with a butyl rubber stopper of $12 \mathrm{~mm}$ thickness. The medium used for growth had the following composition $\left(\mathrm{l}^{-1}\right)$ : $\mathrm{NaCl}, 1.0 \mathrm{~g} ; \mathrm{KCl}, 0.5 \mathrm{~g}$; $\mathrm{MgCl}$. $6 \mathrm{H}_{2} \mathrm{O}, 0.4 \mathrm{~g} ; \mathrm{NH}_{4} \mathrm{Cl}, 0.25 \mathrm{~g} ; \mathrm{CaCl} \cdot 2 \mathrm{H}_{2} \mathrm{O}, 0.1 \mathrm{~g} ; \mathrm{KH}_{2} \mathrm{PO}_{4}, 0.3$; $\mathrm{NaHCO}_{3}, 2.7 \mathrm{~g} ; \mathrm{Na}_{2} \mathrm{~S} \cdot 3 \mathrm{H}_{2} \mathrm{O}, 0.3 \mathrm{~g}$; cysteine hydrochloride, $0.3 \mathrm{~g}$; trace element solution (Wolin et al., 1963), $10 \mathrm{ml}$; vitamin solution (Bryant et al., 1971) $10 \mathrm{ml}$; and $2 \mathrm{ml}$ resazurin indicator solution. The bottles were flushed with $\mathrm{H}_{2} / \mathrm{CO}_{2}(80: 20 \mathrm{v} / \mathrm{v}, 100 \mathrm{kPa})$, which served as a substrate and were pressurized with $\mathrm{N}_{2} / \mathrm{CO}_{2}(80: 20 \mathrm{v} / \mathrm{v}$, $200 \mathrm{kPa})$ to ensure anaerobic conditions. The culture was incubated at $28{ }^{\circ} \mathrm{C}$ in the dark. Growth was monitored by analyzing gas samples with gas chromatography (Agilent GC 6890, with a Flame
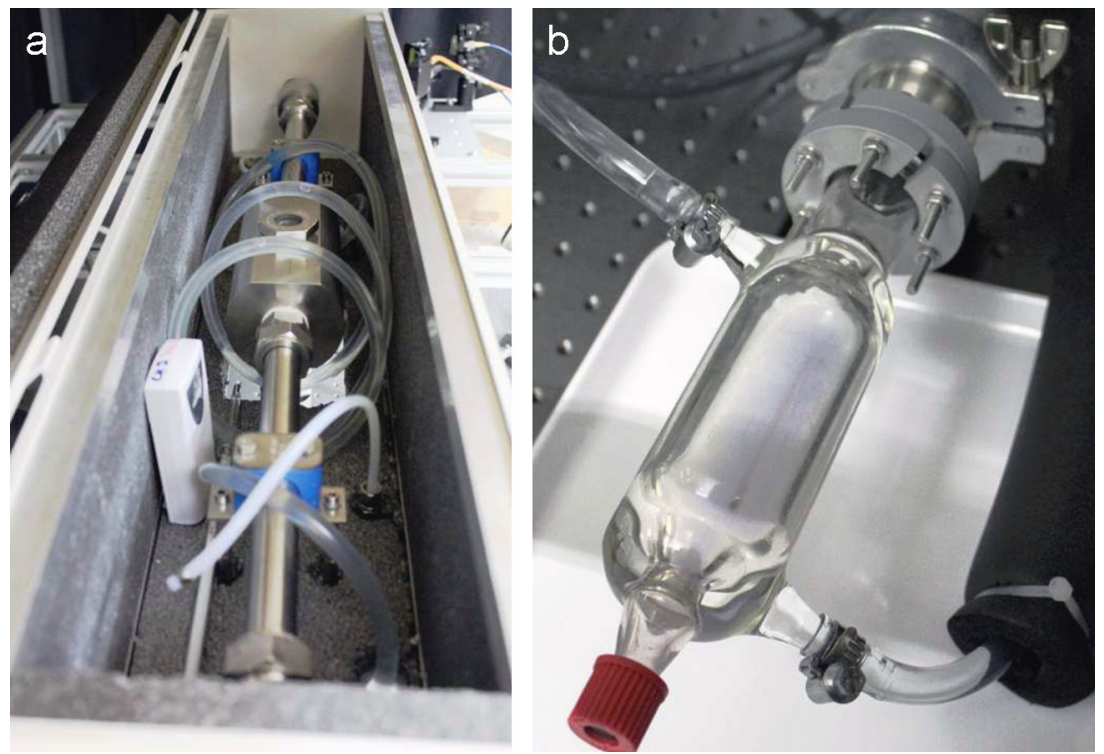

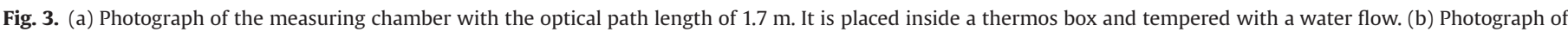

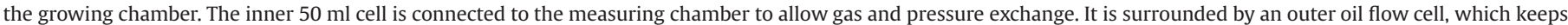
the temperature constant to the set value. 


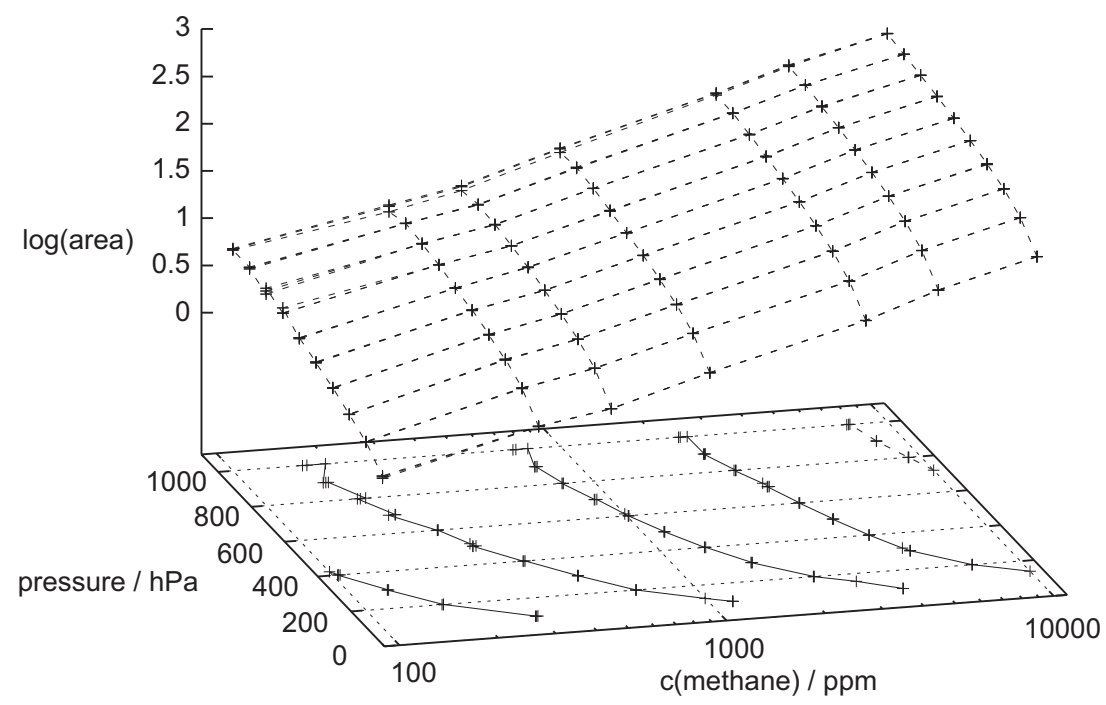

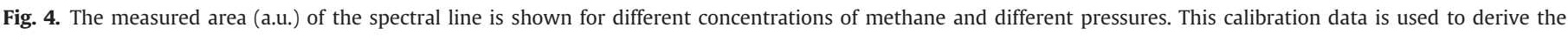
unknown concentration during a simulation sequence, while measuring the area of the spectral peaks in the same way.

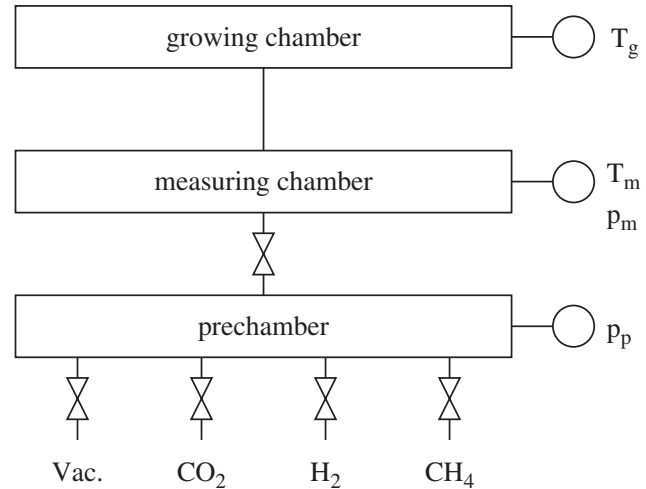

Fig. 5. Schematic diagram of the gas flow between the different simulation system chambers. The temperature $T_{\mathrm{m}}$ of the measuring chamber is held constant at $22{ }^{\circ} \mathrm{C}$ due to stable measuring conditions. The temperature of the growing chamber $T_{\mathrm{g}}$ is varying over time (as shown in Figs. 5 and 6 ). The gas mixture $\left(\mathrm{H}_{2} / \mathrm{CO}_{2}, 80: 20 \% \mathrm{v} / \mathrm{v}\right.$ ) is prepared in the prechamber, $p_{\mathrm{p}}$ and then transferred to the measuring chamber, $p_{\mathrm{m}}$. The initial pressure of the measuring chamber is adjusted to $50 \mathrm{kPa}$, the pressure of the growing chamber is according to that. Methane gas $\left(\mathrm{CH}_{4}\right)$ was filled in from an external source only during calibration measurements.

Ionization Detector and equipped with a Plot Q column, diameter: $530 \mu \mathrm{m}$, length: $15 \mathrm{~m}$; Agilent Technologies, Germany).

\subsection{Preparation of cells of Methanosarcina soligelidi}

After growth in the exponential phase, the cells were harvested through centrifugation (Sigma 6K15-Z3; Sigma-Aldrich, Germany) for $45 \mathrm{~min}$ with $4200 \mathrm{~g}$ at $4{ }^{\circ} \mathrm{C}$, resolved in a fresh sterile medium and transferred to a new serum bottle according to the previous description (see Section 2.4). All preparation steps were performed under strict anaerobic conditions. At the start of each experimental run in the simulation chamber, the cell density was adjusted between $1.0 \times 10^{8}$ and $5.0 \times 10^{8}$ cells $\mathrm{ml}^{-1}$. Cell numbers were determined by Thoma cell counts with a Zeiss Axioscop 2 microscope (Carl Zeiss, Germany).

\subsection{Preparing the initial simulation conditions}

The removable growing chamber was autoclaved and assembled to the measuring chamber (see Section 2.3). The entire system was evacuated for at least $8 \mathrm{~h}$ and the gas mixture of $\mathrm{H}_{2} / \mathrm{CO}_{2}(80: 20 \mathrm{v} / \mathrm{v})$

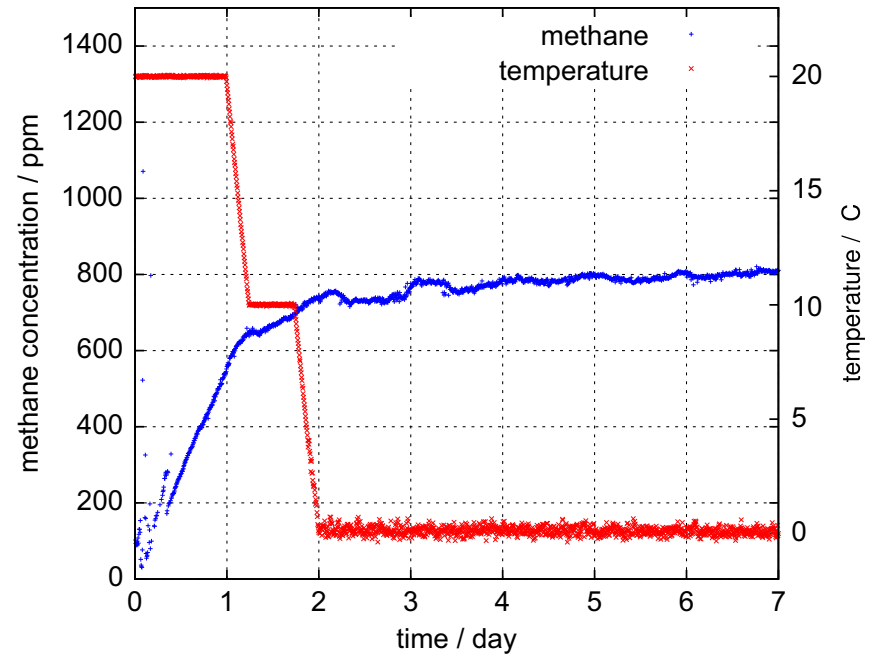

Fig. 6. Methane concentration (blue curve) as a function of time shown stepwise by cooling down from $20^{\circ} \mathrm{C}$ to $0{ }^{\circ} \mathrm{C}$ (red curve) within $24 \mathrm{~h}$ with a intermediate step at $10{ }^{\circ} \mathrm{C}$ for $12 \mathrm{~h}$. The initial pressure was $50 \mathrm{kPa}\left(\mathrm{H}_{2} / \mathrm{CO}_{2} 80: 20 \% \mathrm{v} / \mathrm{v}\right.$ ). (For interpretation of the references to color in this figure legend, the reader is referred to the web version of this article.)

was prepared in the pre-chamber before filling the measuring chamber. The pressure of $50 \mathrm{kPa}$ was adjusted after two flushing steps with the gas mixture. $16.5 \mathrm{ml}$ of the prepared methanogenic archaea cell suspension (see Section 2.5) was injected through a septum using a syringe under sterile conditions. The temperature was automatically varied as a function of time and at the given pressure of $50 \mathrm{kPa}$ the liquid phase stabilized over the measuring period.

\section{Results}

Our developed simulation chamber and measuring system (described in Sections 2.1-2.3) was set up and is operating reliably. In both presented experimental simulation sequences (Figs. 6 and 7) an increase of the methane concentration inside the measuring chamber was detected as a function of time and for different temperatures. Within one week of simulation the initial pressure of $50 \mathrm{kPa}$ decreased to approximately $48 \mathrm{kPa}$. This effect did not 


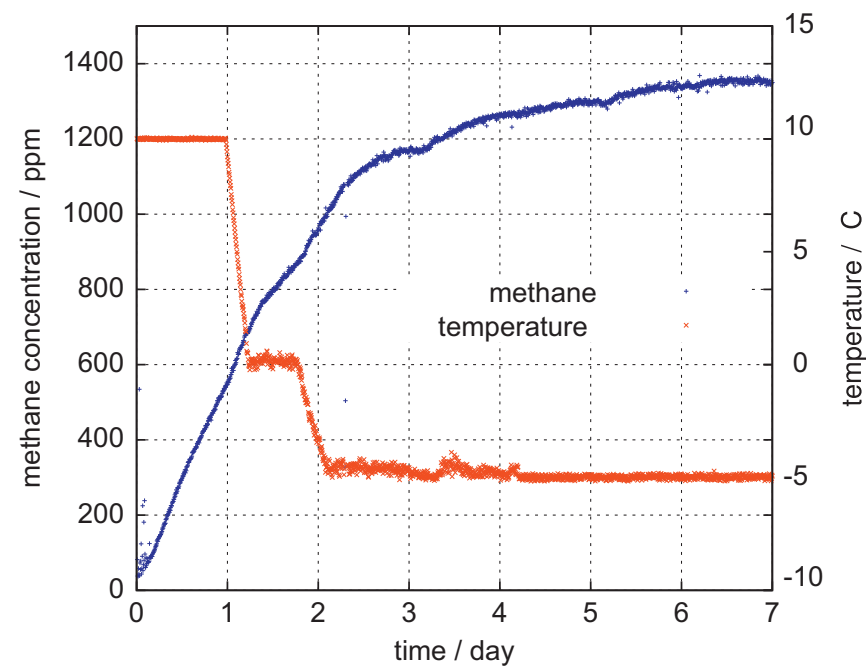

Fig. 7. Methane concentration (blue curve) as a function of time shown stepwise by cooling down from $10{ }^{\circ} \mathrm{C}$ to $-5^{\circ} \mathrm{C}$ (red curve) within $24 \mathrm{~h}$ with a intermediate step at $0{ }^{\circ} \mathrm{C}$ for $12 \mathrm{~h}$. The initial pressure was $50 \mathrm{kPa}\left(\mathrm{H}_{2} / \mathrm{CO}_{2} 80: 20 \% \mathrm{v} / \mathrm{v}\right.$ ). (For interpretation of the references to color in this figure legend, the reader is referred to the web version of this article.)

Table 1

Methane production rates calculated from the increase in the methane concentrations at different temperature intervalls of the two presented experimental simulation sequences shown in Figs. 5 and 6.

\begin{tabular}{|c|c|c|}
\hline \multirow[t]{2}{*}{ Temperature [ ${ }^{\circ}$ ] } & \multicolumn{2}{|c|}{$\mathrm{CH}_{4}$ production rate $\left[\mathrm{nmol} \mathrm{h}^{-1} \mathrm{ml}^{-1}\right]$} \\
\hline & Test 1 (Fig. 5) & Test 2 (Fig. 6) \\
\hline 20.0 & 17 & n.d. \\
\hline 10.0 & 4 & 19 \\
\hline 0.0 & 0.4 & 12 \\
\hline-5.0 & n.d. & 1 \\
\hline
\end{tabular}

n.d. = not determined in the specific test.

occur in tests without organisms, so the biogenic methane formation $\left(4 \mathrm{H}_{2}+\mathrm{CO}_{2} \rightarrow \mathrm{CH}_{4}+2 \mathrm{H}_{2} \mathrm{O}\right)$ might explain this observation. After an initial temperature step of $20^{\circ} \mathrm{C}$ (Fig. 6) and $10{ }^{\circ} \mathrm{C}$ (Fig. 7) for $24 \mathrm{~h}$, the temperature of the growing chamber was decreased to $0{ }^{\circ} \mathrm{C}$ (Fig. 6) and $-5{ }^{\circ} \mathrm{C}$ (Fig. 7), with an intermediate step at $10{ }^{\circ} \mathrm{C}$ (Fig. 6) and $0{ }^{\circ} \mathrm{C}$ (Fig. 7). Each temperature decrease was conducted continuously within $6 \mathrm{~h}$ and the intermediate temperature steps lasted $12 \mathrm{~h}$. Decreasing temperatures resulted directly in decreasing methane accumulation rates, as it can be seen in the stepwise flattening of the methane concentration curves at each temperature step. However, an increase in the methane concentration over time was still observed down to $-5{ }^{\circ} \mathrm{C}$. The methanogenic cell suspension inside of the growing chamber remained liquid at a temperature of $-5{ }^{\circ} \mathrm{C}$. In Table 1 , the calculated methane production rates for each temperature step of both experiments (Figs. 6 and 7) are shown. Although the cell samples for both experiments were treated similarly, a variation in the rates for $10{ }^{\circ} \mathrm{C}$ and $0{ }^{\circ} \mathrm{C}$ occurred. Both experiments were performed separately with separately grown microbial cultures. Hence, slightly different initial cell densities, or cells harvested in not absolutely the exact same phase of growth could be an explanation for the observed differences. One should also mention that the measured data show a small variation of the methane concentration with the periodicity of $24 \mathrm{~h}$. From separate measurements we pinned down the origin of this effect in the imperfect complete thermal isolation of the measuring chamber from the environment. A delay between the temperature variation of the growing cell and the methane growth rate is also visible.
This effect can be derived from the slow diffusion and outgassing of the methane. All these effects unfortunately limit the methane rate determination for these measurements. Nevertheless, a significant change of the methane accumulation rate for the different temperature regimes was observed.

\section{Discussion}

Previous experiments have shown that the archaeal strain Methanosarcina soligelidi is able to survive simulated Martian thermo-physical surface conditions (Morozova et al., 2007). However, during these experiments it was only possible to measure the methane production and survival rates of the cells before and after the simulation sequence. Our results show, that the constructed simulation system is fully functional and methane production could be observed under the tested conditions.

The first experiments show a methanogenic activity of $M$. soligelidi at temperatures down to $-5{ }^{\circ} \mathrm{C}$; lower temperatures were not tested so far. Methane production by a pure culture at temperatures below $0{ }^{\circ} \mathrm{C}$ was only reported previously from Methanogenium frigidum (Franzmann et al., 1997). This strain has been isolated from Ace Lake in Antarctica and was used as one of the reference organisms in the previous study done by Morozova et al. (2007). No methane production of $M$. frigidum was observed after three weeks exposure to Martian thermo-physical surface conditions shown during the experiment of Morozova et al. (2007), whereas the strain M. soligelidi showed nearly the same methane production rate after the simulation compared to the rate measured before the experiment. Incubation experiments done by Wagner et al. (2007) with Holocene permafrost deposits obtained from Samoylov Island in the Lena Delta, northeast Siberia (the same investigation area $M$. soligelidi was isolated from) have shown methanogenic activity at temperatures down to $-6{ }^{\circ} \mathrm{C}$. The methane production rates reported in that study, with incubation with hydrogen as a supplemented energy source, resulted in rates of $0.78 \pm 0.31 \mathrm{nmol} \mathrm{CH}_{4} \mathrm{~h}^{-1} \mathrm{~g}^{-1}$ for $-3{ }^{\circ} \mathrm{C}$ and $0.14 \mathrm{nmol} \mathrm{CH}_{4} \mathrm{~h}^{-1} \mathrm{~g}^{-1}$ for $-6{ }^{\circ} \mathrm{C}$ and match the calculated rates for decreasing temperatures presented here (see Table 1). Other tests performed with soil samples obtained from permafrost of the Kolyma lowland from northeast Eurasian Arctic tundra, reported methanogenesis of the native microbial community even at temperatures down to $-16.5^{\circ} \mathrm{C}$ (Rivkina et al., 2004). However, the presented observation of methanogenic activity of a pure culture at $-5{ }^{\circ} \mathrm{C}$ was not shown before.

The surface of Mars is an extremely cold place with seasonal and diurnal temperature fluctuations reaching from $-138^{\circ} \mathrm{C}$ to $+30{ }^{\circ} \mathrm{C}$ (Jones et al., 2011). The lowest temperature of $-5{ }^{\circ} \mathrm{C}$ tested in this study would only be found on Mars in temporarily variation on the surface, or the first meter below the surface, in mostly equatorial or mid-latitudes. An example for such a periglacial landscape is Utopia Planitia (Ulrich et al., 2012). In persistent timeframes $-5{ }^{\circ} \mathrm{C}$ would merely occur in a depth of several kilometers (Jones et al., 2011). However, M. soligelidi was found to at least survive down to temperatures of $-80^{\circ} \mathrm{C}$, even repeatedly and reversibly within the three weeks Martian simulation experiment (Morozova et al., 2007; Morozova and Wagner, 2007). Additionally, active microbial metabolism, albeit only close to the maintenance level, was reported from an Antarctic ice-lake even at $-13{ }^{\circ} \mathrm{C}$ (Murray et al., 2012). If it comes to terms of stable conditions, the low and highly alternating temperature on Mars seems to be a critical factor. Nevertheless, our experimental temperature is consistent with the temperature maxima in diurnal and seasonal fluctuations in the shallow subsurface and also with the assumed stable temperatures in the deep subsurface of Mars. 
The overall atmospheric pressure on Mars is as low as $0.06 \mathrm{kPa}$. The pressure of $50 \mathrm{kPa}$ used in our experiments equals the hydrostatic pressure which is believed to be found on Mars at depth of approximately 10-20 m below the surface, according to Kral et al. (2011) and to the PT-diagrams for a potential Martian biosphere presented by Jones et al. (2011). Even lower pressures would not be a problem for methanogenic archaea. In the simulation experiment of Morozova et al. (2007) M. soligelidi survived the overall Mars like low pressure of $0.06 \mathrm{kPa}$ for three weeks and was almost unaffected. Also, Kral et al. (2011) have shown that several archaea strains were able to produce methane at pressures down to $0.5 \mathrm{kPa}$. Such a pressure is expected in the shallow first few meters of the subsurface of Mars. In deep subsurface environments, the pressure would of course be higher than that in the shallow subsurface, reaching about $10,000 \mathrm{kPa}$ at $1 \mathrm{~km}$ depth (Jones et al., 2011). On Earth, living methanogens have been isolated from deep subsurface habitats (Kotelnikova et al., 1998; Lever et al., 2013; Shimizu et al., 2011), where the pressure is understandably higher compared to Mars. In addition, the activity of the marine methanogen Methanococcus jannaschii has been proved at a pressure of up to $75,000 \mathrm{kPa}$ (Miller et al., 1988). Therefore, the pressure at either the shallow or in the deep subsurface of Mars would not be a problem for the existence of methanogenic archaea and thus the pressure chosen for this simulation study is suited over this observed pressure regime.

Liquid water was present during the whole simulation sequence of our experiments and thus was easily accessible for the archaeal cells. However, in general the presence of liquid water is a major limiting factor for life as we know it from Earth which includes methanogens. Although, the present day Mars is known to be a dry planet, water might become available periodically at or below the surface. Changing diurnal and seasonal temperatures in addition to pressure conditions result in liquid water in terms of water vapor, interfacial water or in cryobrines (Möhlmann, 2010a, 2010b; Möhlmann and Thomson, 2011). Furthermore, liquid-like adsorption water in potential subsurface habitats could support life (Möhlmann, 2005). In a previous study, M. soligelidi has shown high desiccation tolerance (Morozova and Wagner, 2007). During the three week long Martian thermo-physical simulation experiment done by Morozova et al. (2007), the water activity was varying between $a_{\mathrm{w}} 0.1$ and 0.9 due to diurnal water vapor pressure fluctuations, which had no influence on the viability of M. soligelidi tested before and after the exposure. Other methanogenic strains, especially Methanosarcina barkeri, have also been shown to survive long term desiccation for more than 300 days (Kral et al., 2011). Hence, even solely periodically available liquid water does not rule out the possible existence of methanogens in the Martian subsurface and the permanent liquid phase during the presented simulation experiments is not necessarily a contradiction to Martian conditions.

As chemolithotrophic microorganisms, methanogenic archaea are able to grow with carbon dioxide and molecular hydrogen as the only carbon and energy sources. Therefore, we used a gas mixture of $\mathrm{H}_{2} / \mathrm{CO}_{2}(80: 20 \% \mathrm{v} / \mathrm{v})$ within the simulation, which serves as a good stoichiometric ratio for hydrogenotrophic methanogenesis $\left(4 \mathrm{H}_{2}+\mathrm{CO}_{2} \rightarrow \mathrm{CH}_{4}+2 \mathrm{H}_{2} \mathrm{O}\right)$. Carbon dioxide is commonly distributed in the Martian atmosphere at about 95\%, but hydrogen could be detected only in trace amounts (Oze and Sharma, 2005). On Earth, molecular hydrogen is not available in such high concentrations as it is not on Mars, but it has been reported to be dissolved in groundwater at $\mathrm{mM}$ concentrations for subsurface and deep subsurface microbial ecosystems (Sherwood Lollar et al. 2007). Not all of these habitats were characterized by hydrogen produced from geothermal activity, whose occurrence on Mars is uncertain (Krasnoplosky, 2006), but it was produced through alteration processes of basaltic crust in stable ancient Precambrian cratons, which serve as good Earth analogs for a single-plate planet like Mars (Sherwood Lollar et al., 2007). In the Martian subsurface, direct interaction with liquid interfacial water may also be a source of hydrogen due to the release of protons. Furthermore, it has been shown on Earth that with interspecies hydrogen transfer (e.g. Conrad and Babbel, 1989; Ishii et al., 2005), electrons (as hydrogen or formate) which are generated in one microorganism species, can be transferred to another. This might also be a possibility for methanogens in a potential Martian ecosystem to obtain hydrogen as an energy source in a hydrogen limited environment. In addition, methanogens on Earth are also able to substitute hydrogen with carbon monoxide (O'Brien et al., 1984), which has been detected in the Martian atmosphere in varying concentrations reaching from 400 to more than $2500 \mathrm{ppm}$ (Sindoni et al., 2011). Accordingly, high concentrations of molecular hydrogen as substrate for methanogenesis are consistent with Martian subsurface simulation conditions.

\section{Conclusion}

We have shown that the developed simulation and measuring system is fully functional and ready to operate with Mars (subsurface) analog conditions. At temperatures down to $-5{ }^{\circ} \mathrm{C}$ metabolic activity of the pure archaeon strain Methanosarcina soligelidi could be detected, which has not been reported for a single methanogenic strain before. This result and the findings of previous reported studies have shown that methanogenic archaea (especially those from permafrost environments) can be regarded as ideal model organisms for possible life on Mars. Although, they are able to survive the harsh thermo-physical conditions found on the Martian surface (Morozova et al., 2007) and also high doses of UV and ionizing radiation (comparable to Deinococcus radiodurans; Wagner et al., 2013) as they would occur on the surface of Mars, the subsurface seems to be a more suitable habitat due to more stable temperature conditions and the higher probability of liquid water. The conditions of potential Martian (deep) subsurface habitats were initially tested in our experiments. Further tests will be needed to check the potential of our model organism Methanosarcina soligelidi for methanogenic activity under simulated Martian shallow subsurface conditions. These can be conducted with presence of Mars analog soil simulates, under colder temperature, lower pressure and humidity, also over diurnal variations which are representative for other possible habitats on Mars.

\section{Acknowledgments}

This work was financed by the Helmholtz Association through the HGF Alliance "Planetary Evolution and Life". The measuring chamber was constructed by Dr. Wernecke Feuchtemesstechnik GmbH (Potsdam, Germany). We thank Yuriy Zakrevskyy (University of Potsdam, Germany) and Undrakh Bekhtur (present affiliation: RST Radar und Systemtechnik GmbH, Salem, Germany) for their provided support during the development of the simulation and measuring system.

\section{References}

Barbier, A.B., Dziduch, I., Liebner, S., Ganzert, L., Lantuit, H., Pollard, W., Wagner, D., 2012. Methane-cycling communities in a permafrost-affected soil on Herschel Island, Western Canadian Arctic: active layer profiling of mcrA and pmoA genes. FEMS Microbiology Ecology 82 , 287-302.

Bischoff, J., Mangelsdorf, K., Gattinger, A., Schloter, M., Kurchatova, A., Herzschuh, U., Wagner, D., 2013. Response of methanogenic archaea to Late Pleistocene and Holocene climate changes in the Siberian Arctic. Global Biogeochemical Cycles 27, 305-317. 
Boston, P.J., Ivanov, M.V., McKay, C.P., 1992. On the possibility of chemosynthetic ecosystems in subsurface habitats on Mars. Icarus 95, 300-308.

Bruhn, D., Møller, I.M., Mikkelsen, T.N., Ambus, P., 2012. Terrestrial plant methane production and emission. Physiologia Plantarum 144, 201-209.

Bryant, M.P., Tzeng, S.F., Robinson, J.M., Joyner Jr., A.E., 1971. Nutrient requirements of methanogenic bacteria. Advances in Chemistry Series 105, 23-40.

Carr, M.H., 1989. Recharge of the early atmosphere of Mars by impact-induced release of $\mathrm{CO}_{2}$. Icarus $79,311-327$.

Carr, M.H., 1996. Water on Mars. Oxford University Press, New York, USA.

Conrad, R., Babbel, M., 1989. Effect of dilution on methanogenesis, hydrogen turnover and interspecies hydrogen transfer in anoxic paddy soil. FEMS Microbiology Ecology 62, 21-28.

Cubillas, A.M., Lazaro, J.M., Conde, O.M., Petrovich, M.N., Lopez-Higuera, J.M., 2009. Gas sensor based on photonic crystal fibres in the $2 \mathrm{v} 3$ and $v 2+2 \mathrm{v} 3$ vibrational bands of methane. Sensors 9, 6261-6272.

Demtröder, W., 2007. Laser Spectroscopy. Springer, Heidelberg, Germany.

Durham, R., Schmunk, R.B., Chamberlain, J.W., 1989. Comparative analysis of the atmospheres of early Earth and Mars. Advances in Space Research 9, 139-142.

Formisano, V., Atreya, S., Encrenaz, T., Ignatiev, N., Giuranna, M., 2004. Detection of methane in the atmosphere of Mars. Science 306, 1758-1761.

Franzmann, P.D., Liu, Y., Balkwill, D.L., Aldrich, H.C., Conway de Macario, E., Boone, D.R., 1997. Methanogenium frigidum sp. nov., a psychrophilic, H2-using methanogen from Ace Lake, Antarctica. International Journal of Systematic Bacteriology 47, 1068-1072.

Geminale, A., Formisano, V., Giuranna, M., 2008. Methane in Martian atmosphere: average spatial, diurnal, and seasonal behavior. Planetary and Space Science 56, 1194-1203.

Geminale, A., Formisano, V., Sindoni, G., 2011. Mapping methane in Martian atmosphere with PFS-MEX data. Planetary and Space Science 59, 137-148.

Gough, V.R., Tolbert, M.A., McKay, C.P., Toon, O.B., 2010. Methane adsorption on Martian soil analog: an abiogenic explanation for methane variability in the Martian atmosphere. Icarus 207, 165-174.

Ishii, S., Kosaka, T., Hori, K., Hotta, Y., Watanabe, K., 2005. Coaggregation faciliates interspecies hydrogen transfer between Pelotomaculum thermopropionicum and Methanothermobacter thermoautotrophicus. Applied and Environmental Microbiology 71, 7838-7845.

Jakosky, B.M., Nealson, K.H., Bakermans, C., Ley, R.E., Mellon, M.T., 2003. Subfreezing activity of microorganisms and the potential habitability of Mars' polar regions. Astrobiology 3, 343-350.

Jones, E.G., Lineweaver, C.H., Clarke, J.D., 2011. An extensive phase space for the potential Martian biosphere. Astrobiology 11, 1017-1033.

Kotelnikova, S., Macario, A.J.L., Pedersen, K., 1998. Methanobacterium subterraneurn sp. nov., a new alkaliphilic, eurythermic and halotolerant methanogen isolated from deep granitic groundwater. International Journal of Systematic Bacteriology $48,357-367$.

Kral, T.A., Bekkum, C.R., McKay, C.P., 2004. Growth of methanogens on a Mars soil simulant. Origins of Life and Evolution of Biospheres 34, 615-626.

Kral, T.A., Altheide, T.S., Lueders, A.E., Schuerger, A.C., 2011. Low pressure and desiccation effects on methanogenisis: implications for life on Mars. Planetary and Space Science 59, 264-270.

Krasnopolsky, V.A., Maillard, J.P., Owen, T.C., 2004. Detection of methane in the Martian atmosphere: evidence for life? Icarus 172, 537-547.

Krasnopolsky, V.A., 2006. Some problems related to the origin of methane on Mars. Icarus 180, 359-367.

Lever, M.A., Rouxel, O., Alt, J.C., Shimizu, N., Ono, S., Coggon, R.M., Shanks III, W.C., Lapham, L., Elvert, M., Prieto-Mollar, X., Hinrichs, K.-U., Inagaki, F., Teske, A., 2013. Evidence for microbial carbon and sulfur cycling in deeply buried ridge flank basalt. Science 339, 1305-1308.

McKay, C.P., Davis, W., 1991. Duration of liquid water habitats on early Mars. Icarus 90, 214-221.

McKay, C.P., Friedman, E.I., Wharton, R.A., Davies, W.L., 1992. History of water on Mars: a biological perspective. Advances in Space Research 12, 231-238.

Michalski, J.R., Cuadros, J., Niles, P.B., Parnell, J., Rogers, A.D., Wright, S.P., 2013. Groundwater activity on Mars and implications for a deep biosphere. Nature Geoscience 6, 133-138.

Miller, J.F., Shah, N.N., Nelson, C.M., Ludlow, J.M., Clark, D.S., 1988. Pressure and temperature effects on growth and methane production of the extreme thermophile Methanococcus jannaschii. Applied and Environmental Microbiology $54,3039-3042$.

Möhlmann, D., 2005. Adsorption water-related potential chemical and biological processes in the upper Martian surface. Astrobiology 5, 770-777.

Möhlmann, D., 2010a. Temporary liquid water in the upper snow/ice sub-surface on Mars? Icarus 207, 140-148.
Möhlmann, D., 2010b. The three types of liquid water in the surface of present Mars. International Journal of Astrobiology 9, 45-49.

Möhlmann, D., Thomson, K., 2011. Properties of cryobrines on Mars. Icarus 212, $123-130$.

Morozova, D., Möhlmann, D., Wagner, D., 2007. Survival of methanogenic archaea from Siberian permafrost under simulated Martian thermal conditions. Origins of Life and Evolution of Biospheres 37, 189-200.

Morozova, D., Wagner, D., 2007. Stress response of methanogenic archaea from Siberian permafrost compared to methanogens from non-permafrost habitats. FEMS Microbiology Ecology 61, 16-25.

Mumma, M.J., Villanueva, G.L., Novak, R.E., Hewagama, T., Bonev, B.P., DiSanti, M.A. Mandell, A.M., Smith, M.D., 2009. Strong release of methane on Mars in northern summer 2003. Science 323, 1041-1045.

Murray, A.E., Kenig, F., Fritsen, C.H., McKay, C.P., Cawley, K.M., Edwards, R., Kuhn, E. McKnight, D.M., Ostrom, N.E., Peng, V., Ponce, A., Priscu, J.C., Samarkin, V., Townsend, A.T., Wagh, P., Young, S.A., Yung, P.T., Doran, P.T., 2012. Microbial life at $-13{ }^{\circ} \mathrm{C}$ in the brine of an ice-sealed Antarctic lake. In: PNAS, USA 2012; November 26, 2012. doi:pnas.org/cgi/doi/10.1073/pnas.1208607109 (published ahead of print).

O’Brien, J.M., Wolkin, R.H., Moench, T.T., Morgan, J.B., Zeikus, J.G., 1984. Association of hydrogen metabolism with unitrophic or mixotrophic growth of Methanosarcina barkeri on carbon monoxide. Journal of Bacteriology 158, 373-375.

Oze, C., Sharma, M., 2005. Have olivine, will gas: serpentinization and the abiogenic production of methane on Mars. Geophysical Research Letters 32, L10203.

Rivkina, E., Laurinavichius, K., McGarth, J., Tiedje, J., Shcherbakova, V., Gilichinsky, D., 2004. Microbial life in permafrost. Advances in Space Research 33 $1215-1221$.

Rothman, L.S., Gordon, I.E., Barbe, A., Benner, D.C., Bernath, P.F., Birk, M., Boudon, V., Brown, L.R., Campargue, A., Champion, J.-P., Chance, K., Coudert, L.H., Dana, V. Devi, V.M., Fally, S., Flaud, J.-M., Gamache, R.R., Goldman, A., Jacquemart, D., Kleiner, I., Lacome, N., Lafferty, W., Mandin, J.-Y., Massie, S.T., Mikhailenko, S.N., Miller, C.E., Moazzen-Ahmadi, N., Naumenko, O.V., Nikitin, A.V., Orphal, J., Perevalov, V.I., Perrin, A., Predoi-Cross, A., Rinsland, C.P., Rotger, M., Simeckova, M., Smith, M.A.H., Sung, K., Tashkun, S.A., Tennyson, J., Toth, R.A., Vandaele, A.C. Vander Auwera, J., 2009. The HITRAN 2008 molecular spectroscopic database. Journal of Quantitative Spectroscopy and Radiative Transfer 110, 533-572.

Sherwood Lollar, B., Voglesonger, K., Lin, L.-H., Lacrampe-Couloume, G., Telling, J., Abrajano, T.A., Onstott, T.C., Pratt, L.M., 2007. Hydrogeologic controls on episodic $\mathrm{H}_{2}$ release from Precambrian fractured rocks - energy for deep subsurface life on Earth and Mars. Astrobiology 7, 971-986.

Shimizu, S., Upadhye, R., Ishijima, Y., Naganuma, T., 2011. Methanosarcina horonobensis sp. nov., a methanogenic archaeon isolated from a deep subsurface Miocene formation. International Journal of Systematic and Evolutionary Microbiology 61, 2503-2507.

Sindoni, G., Formisano, V., Geminale, A., 2011. Observations of water vapor and carbon monoxide in the Martian atmosphere with the SWC of PFS/MEX. Planetary and Space Science 59, 149-162.

Ulrich, M., Wagner, D., Hauber, E., de Vera, J.-P., Schirrmeister, L., 2012. Habitable periglacial landscapes in Martian mid-latitudes. Icarus 212, 345-357.

Vance, S., Harnmeijer, J., Kimura, J., Hussmann, H., DeMartin, B., Brown, J.M., 2007. Hydrothermal systems in small ocean planets. Astrobiology 7 (6), 987-1005.

Wagner, D., Gattinger, A., Embacher, A., Pfeiffer, E.-M., Schloter, M., Lipski, A., 2007 Methanogenic activity and biomass in Holocene permafrost deposits of the Lena Delta, Siberain Arctic and its implication for the global methane budget. Global Change Biology 13, 1089-1099.

Wagner, D., Schirmack, J., Ganzert, L., Morozova, D., Mangelsdorf, K., 2013. Methanosarcina soligelidi sp. nov., a desiccation and freeze-thaw resistant methanogenic archaeon isolated from a Siberian permafrost-affected soil International Journal of Systematic and Evolutionary Microbiology 63, 2986-2991.

Webster, C.R., Mahaffy, P.R., Atreya, S.K., Flesch, G.J., Christensen, L.E., Farley, K.A., MSL Science Team, 2013. Measurements of Mars methane at Gale Crater by the SAM Tunable Laser Spectrometer on the Curiosity Rover. In: Proceedings of 44th Lunar and Planetary Science Conference 2013.

Weiss, B.P., Yung, Y.L., Nealson, K.H., 2000. Atmospheric energy for subsurface life on Mars? Proceedings of the National Academy of Sciences USA 97, 1395-1399.

Wolin, E.A., Wolin, M.J., Wolfe, R.S., 1963. Formation of methane by bacterial extracts. Journal of Biological Chemistry 238, 2882-2886.

Zahnle, K., Freedman, R.S., Catling, D.C., 2011. Is there methane on Mars? Icarus 212, 493-503.

Zakrevskyy, Y., Ritschel, T., Dosche, C., Löhmannsröben, H.-G., 2012. Quantitative calibration- and reference-free wavelength modulation spectroscopy. Infrared Physics and Technology 55 (2-3), 183-190. 